\title{
Drawing Glasgow School of Art: the graphics of reconstruction.
}

A reflection on the drawings of Mackintosh's Glasgow School of Art following 2018's second devastating fire, considering how that event changes relations between drawing and building in the architect's work.

Johnny Rodger

In the wake of the second fire in four years at the Glasgow School of Art on $16^{\text {th }}$ June 2018, a further round of examination and assessment of the building, and of Mackintosh's work both there and in general, will doubtless take place. It is a practical necessity to assess whether the building can be rebuilt from the ruins, what type of reproduction is desired and/or possible, and what sort of materials are available in the wreckage, in archives and in store to assemble the expertise, know-how and understanding that would allow for any rebuilding. Should a decision be made not to rebuild, then an archiving and assessment of the original through remaining materials will likely be staged to preserve its memory and history for posterity.

This article proposes that the study of the history of Charles Rennie Mackintosh's drawing, of his Glasgow School of Art building and of the institution of Glasgow School of Art itself, should be central to research work towards any coming reassessment of Mackintosh heritage. At its most simple, this is so because drawing was Mackintosh's art: he did not actually engage in the construction, in the making of materials, the placing stone upon stone, or the carving of timber. The drawings were his art, and that constitutes a powerful argument for insisting that the building is rebuilt, because it doesn't particularly matter who carries out that material labour, as long as they are competent and professional and take what instruction they can from Mackintosh's drawings. Yet perhaps things are more complicated than that? For if the real work consists in the drawings, then why rebuild the physical construction? This is not a 'Raphael with no Hands'-type argument, but rather to ask about the role that the building plays in the production of an architectural project. Is the notion that physical construction must be an outcome a fetishistically narrow view of the scope of an architectural project? 


\section{The Glasgow School of Art as a drawing machine}

Charles Rennie Mackintosh's architectural masterwork, the Glasgow School of Art (1897-1909), can be said to occupy a unique and emblematic position in the history of drawing. It draws graphic culture, in all its disparate modes and manifestations, together in one establishment. The edifice itself is both an outcome and a demonstration of the virtuosity in the drawing skills to which the institution has dedicated its teaching and study since its inception in 1845. It is also a building which is most seriously understood in its complexity through depiction in drawing. Mackintosh was able to construct such a complex building partly because of the number of historical styles and modes of building upon which he drew and hybridised, and which influenced his own mature way of working, including Scottish vernacular and Baronial, English Arts-and-Crafts, Japanese forms, the latest technology to which he was exposed in the great industrial city of Glasgow, and the Secessionist movement of central Europe. Ultimately, however as Andrew MacMillan noted, Mackintosh produced an object which was a harbinger of the modern inasmuch as it existed in its own authentic right and not as a creation of any one particular style. It has been seen as '[...] the first building [...] to derive its authority from its own intrinsic nature rather than from its employment of any stylistic or historical canon. ${ }^{1}$ Furthermore, the building gathers and shelters a community which focuses its pedagogic energies on the study and practice of drawing, while at the same time the fascinating structure of the building has served that community as an exemplary model for ongoing practice, research and experimentation in drawing skills.

As Paul Clarke put it, in Deleuzian terminology, at a talk at the Glasgow School of Art, the Mackintosh building, in those various levels of operation, can be seen as a 'drawing machine'. It is to the productions and the workings of the 'machine' that this article is dedicated: the focus on one particular aspect of that machination, namely architectural drawing. Thus, the question addressed here is: in what manner was this building, originally a result of drawing, developed further as both an exemplary host and a model for drawing. To address those questions, it is necessary to examine the types and conditions of drawing, and also the intention behind the drawings - namely to design new work or to analyse or demonstrate existing work - and the technological state of construction techniques and their relationship to drawing. In this essay, these examinations will trace various strands of the history of this building's involvement in, and indeed, centrality to the practice of drawing.

\section{Drawing and material}


As we are concerned particularly with architectural drawing here - and not any of the many other types of drawing which have taken place in that drawing machine of the Mackintosh building - it is useful to bear in mind the scope of the many strands of architectural drawing that have occurred. For the purposes of this study, we could note that there exists a special relationship between looking and making in architectural drawing: that the architectural drawing points us, most usually, towards a material object which exists separately from the drawing and authentically in the world on its own. The architectural drawing indeed could be said to have a special ontological relationship to the material piece of architecture to which it relates. As such, the classical concept of mimesis, explored and rejected by Plato in The Republic (see Books III and X), ${ }^{2}$ as a representation by a subjective artist of nature or an object in the world (such as a bed in Book X of The Republic), cannot strictly be applied to architectural drawings. At its most literal level of inapplicability, this would be because the first design drawings of an architectural project claim to represent something which does not yet have a material existence in the world. Hence, architectural drawings remain prospective, but not quite ideal in the Platonic sense because of their part in a routine or utilitarian process which has an instructional or intentional relation towards the making of a final material object. Beyond the actual stage of designing or building the architectural work, an architectural drawing can be made in order to expose or display certain compositional or structural elements in the make-up of the building which are not immediately apparent to the viewer or user of the building. Further, detail drawings or studies might be made to analyse and understand particular building or structural techniques, documenting how the building has been made. These latter strands of architectural drawing do belong to the representational type - exceptionally - however they can no more be criticised as mimetic than the design drawings, for they are not simply seen from one subjective point of view, but are diegetic, that is, they seek to be objective or all-knowing, by presenting the object without any perspectival or subjective viewpoints, as Raphael pointed out to Pope Leo X in 1519 when he theorised the plan, section and elevation as the three fundamental types of architectural drawing. ${ }^{3}$ Hence, a vital component of 'looking' - in that relationship between 'looking' and 'making' in the architectural drawing - is the act of measuring (as indeed recommended by Plato in book $X$ of the Republic to overcome the problems of mimesis), which latter ensures that the drawing is not subjective, or mimetic, but objective, diegetic and thus dependable for making, or for understanding the making process.

The simplest and most effective way to establish the importance of Mackintosh's School of Art in the context of that history is to study the 
evidence of the drawings themselves. In approaching this task, the archive at the School is of inestimable value. So broad are the graphic resources in the archive that one must choose carefully how best that history, as described above, can be demonstrated in published form. Hence, a selection of drawings figured as representative of that history is presented here, alongside a brief textual commentary. A rough preliminary categorisation of these drawings comprises: Mackintosh's drawings for the whole building, of which only the eastern half was completed in 1899; Mackintosh's subsequent design drawings of 1907 for the completion of the western half of the building; Mackintosh's presentation drawings made of the completed building in 1910; measured drawings of the building made for student theses and dissertations from the 1970 s onwards; drawings made in the 1980s and ' 90 s by students and staff at GSA either to establish certain technical 'facts' in the history of architecture in general or of this building in particular, or to institute a more secure, broad and formal published platform for the study of the building; and drawings made for student dissertations in the 2000s to complete the portfolio of drawings by Mackintosh and to supplement the range of critical tools available for understanding the building.

\section{Drawing Mackintosh}

The story of the development of Mackintosh's design for the Glasgow School of Art can be traced through the drawings he made at different stages in the two-phase construction, 1897-99 and 1907-09, of the building. The drawings themselves, including 1899, 1907 and 1910 plans and elevations can be seen in the GSA archive and are reproduced here. Critical analysis of the development of the building through drawing has been extensive, published both in arq and elsewhere, ${ }^{4}$ though I will provide a brief summary here.

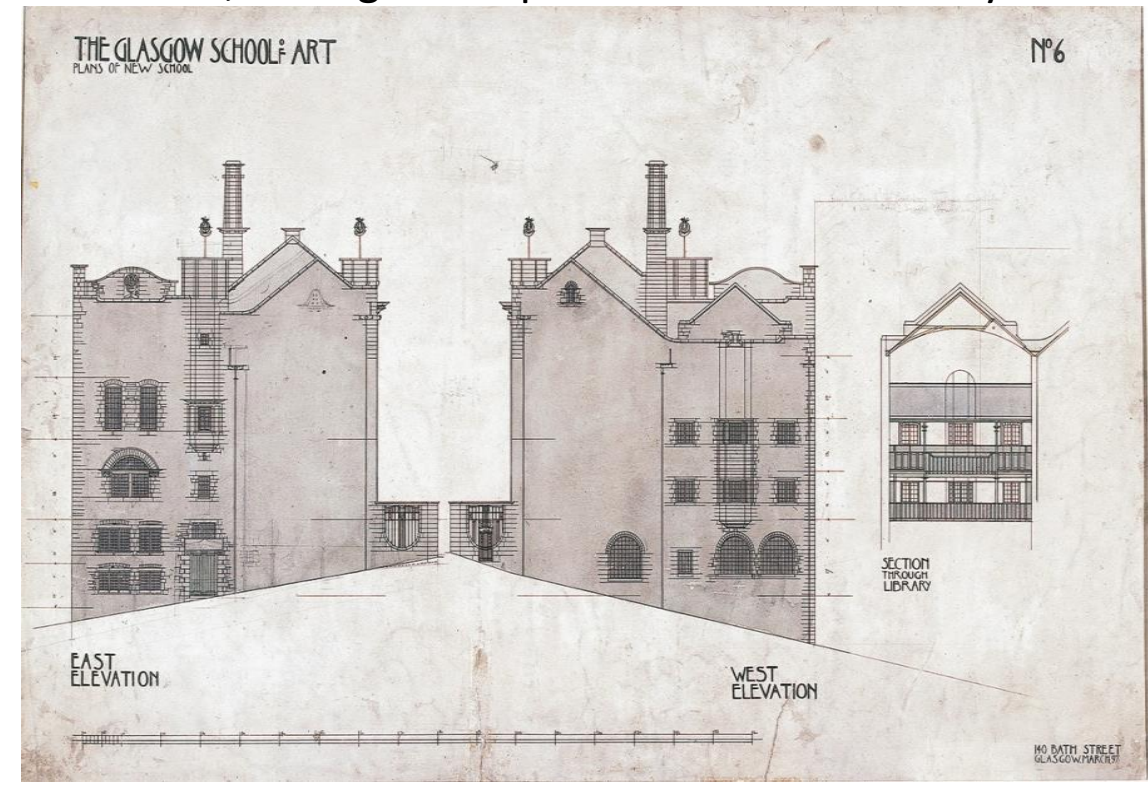


In the 1899 elevation drawing [1], Mackintosh has already built an eastern elevation which adopts the forms of the Baronial style, notably the oriel window and tower which can be traced to the influence of sketches he had made of traditional works such as Maybole Castle. At this stage the as yet unbuilt west elevation is prospectively drawn in a similar style.

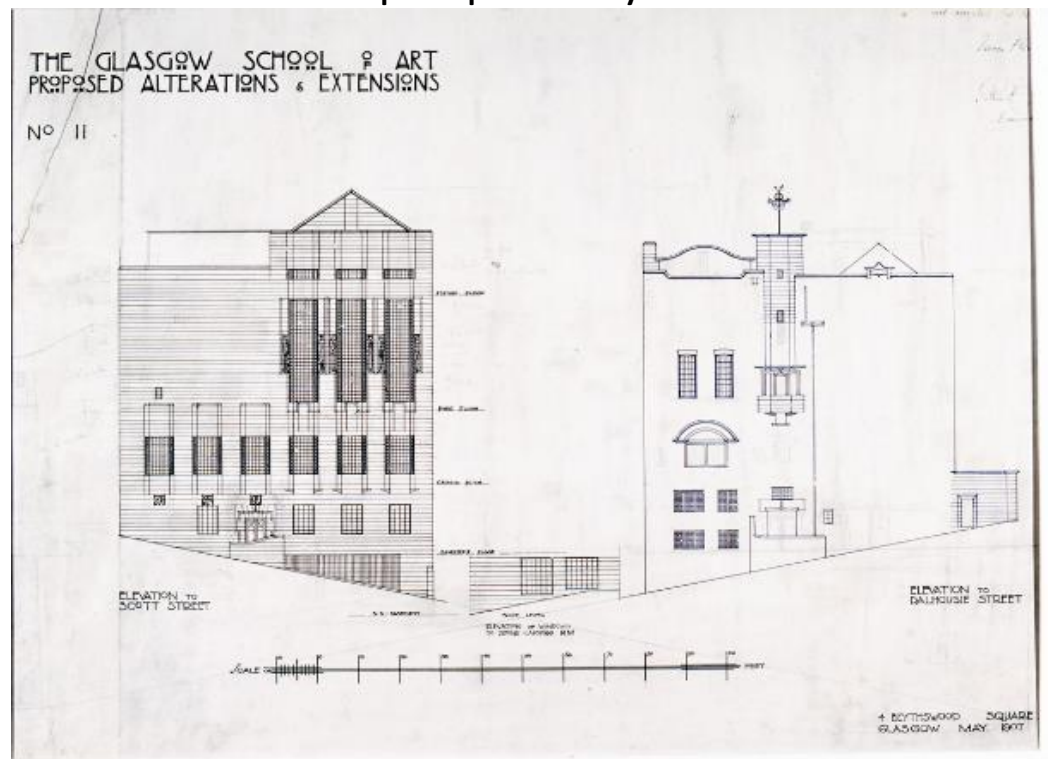

When he actually comes to build the west elevation in 1907 [2] however, we see that his design has changed much over the interim. Indeed, if we then examine the 1910 presentation drawings for the completed building [3], again we see much development and change from the 1907 design version.

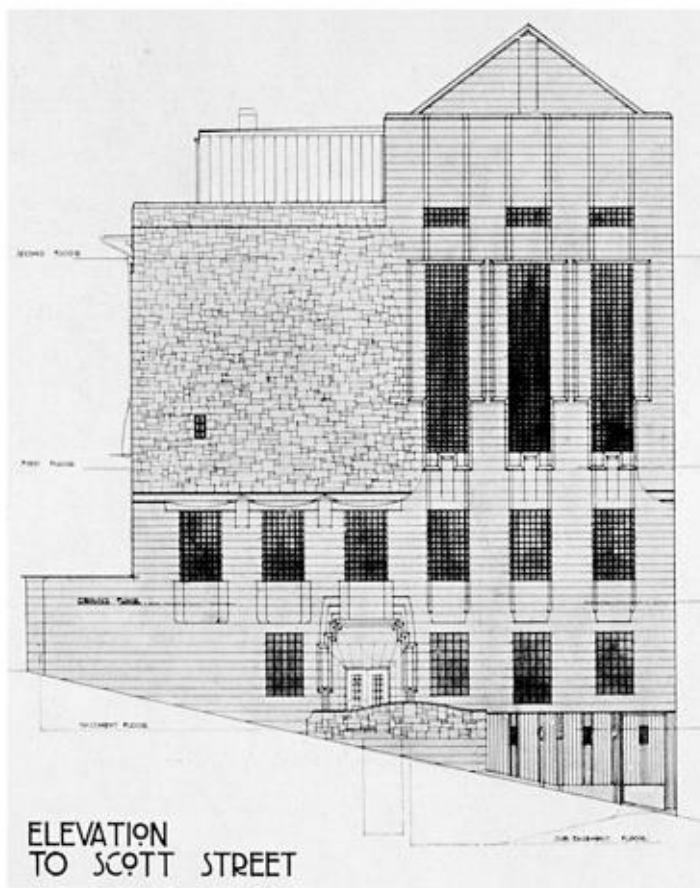


The final version of the west elevation is a highly individualised and expressionistic hybrid, with the sheer verticality of its $60 \mathrm{ft}$ oriel windows which evidences elements of Secessionist, and arguably even Cubist influence. ${ }^{5}$ Through these drawings we see that Mackintosh moved from a literal 'copyist' approach to the Baronial forms towards an understanding of the Baronial architectonics as a mode of conception of, and operation with, space and material, rather than as mere style. This was partly achieved through his study and readings of McGibbon and Ross's work published in the 1890s on Scottish architecture from the twelfth to the eighteenth centuries. ${ }^{6}$

Whereas an architect operating in the dominant Beaux-Arts-trained mode of the mid- to late-nineteenth century was principally concerned with 'composition' - with the magnificently precise planning of the building, the strict and symmetrical relationship of parts to the whole, plan to section and so on - Mackintosh, through his interest in the Scottish Baronial, demonstrated an early and then abiding obsession with 'character' and a versatile sensitivity for the creation of particularised and expressive structure. ${ }^{7}$ Thus, in the western elevation, we no longer see that reproduction of pastiche 'frozen' forms of the historical Baronial style as in the drawings of 1897. Instead of the finished forms, it is the creative impulse behind the constructions of the Baronial era which informs the task and the approach to the materials and structure. This creative impulse allows Mackintosh to develop the form of the structure as a necessary expression, neither as a pastiche reproduction of existent forms, nor simply as a result of the dictates of the latest technology which is employed, but as an object which, as MacMillan says, 'derive(s) its authority from its own intrinsic nature' and is designed and built by human hand and eye.

The 'rediscovery' of Mackintosh, and acknowledgement of his significance in architectural history after a long period of neglect following his death, meant that there has also been a flourishing culture of graphic analysis of his work. The narrative of this 'rediscovery' of Mackintosh can be traced through critical work in the 1950 s by Howarth ${ }^{8}$ and Pevsner, ${ }^{9}$ and the films of Murray Grigor in the $60 \mathrm{~s}$ and $70 \mathrm{~s} .{ }^{10} \mathrm{It}$ is significant for the thesis here that part of that 'rediscovery' includes the establishment of the eponymous Mackintosh School of Architecture at Glasgow School of Art in 1968. From early in the history of the school, students and staff have engaged in studies of the architectural and graphic heritage of Mackintosh in the Glasgow School of Art. The most important and influential of these studies could broadly be categorised in terms of their focus on accuracy of representation, analysis of detail, study of technical aspects, and of critical meditation. A brief outline and 
presentation of samples of each of those categories of graphical studies follows.

From early in the history of this research, doubts had been raised about the accuracy of existing drawings of the building by Mackintosh - namely those from 1899, 1907 and 1910. Students at GSA began to carry out measured studies of the building for degree dissertation work. Notable amongst these completed dissertations were those of Peter Porteous and Paul Spear's collaboration in 1971 (see image of ground floor plan here), ${ }^{11}$ [4] and William Coltart and lain W. Bailey's work produced in 1982. ${ }^{12}$

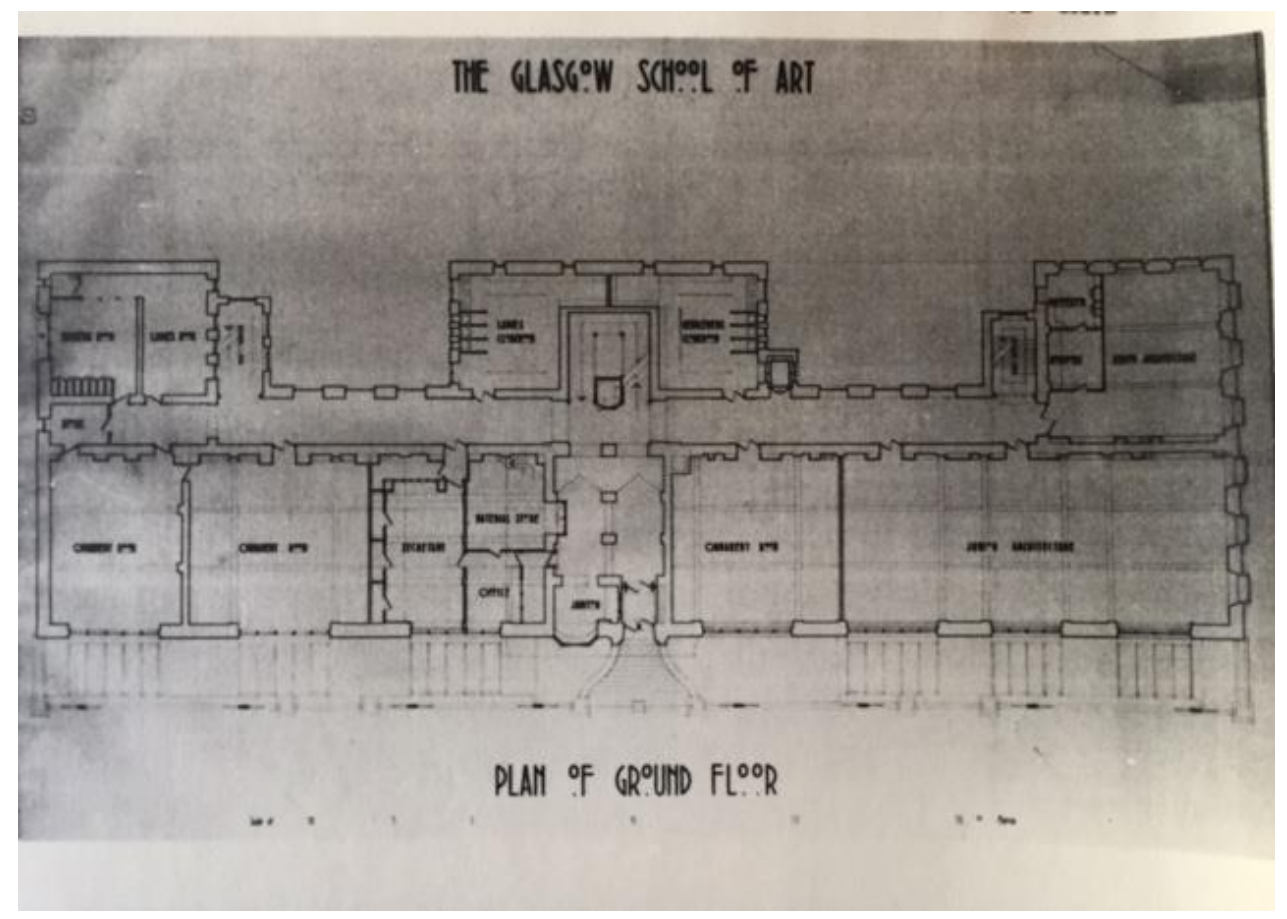

On the first page of Porteous and Spear's study, they claim that they made these drawings because existing drawings are 'extremely inaccurate' and that 'few records exist of the 'as built' layout of the building'. Equally, on page 1 of their dissertation, Coltart and Bailey write that 'there are few drawings which actually record the building as complete in 1909'. Ultimately these implied criticisms of Mackintosh's presentation drawings were proved correct when in extremis the rebuild team after the 2014 fire discovered that the Mackintosh drawings were neither accurate nor detailed enough to use for their task.

The question of detail is also one to which the work of staff and students at the Mackintosh School of Architecture has paid much attention. Besides the full sets of measured drawings, many studies through drawing have also been made of individual parts, features and details of the building. These include John Harrigan's study of the central bay of the GSA $(1987)[5,6],{ }^{13}$ (including 
bas relief frieze, plans, sections and axonometrics) accompanied by a claim that 'much of that work [Mackintosh's] lacks any architectural critique', and William Cooper and Peter Moir's detailed and often coloured measured study of the doors and doorways in Glasgow School of Art (1983). ${ }^{14}$

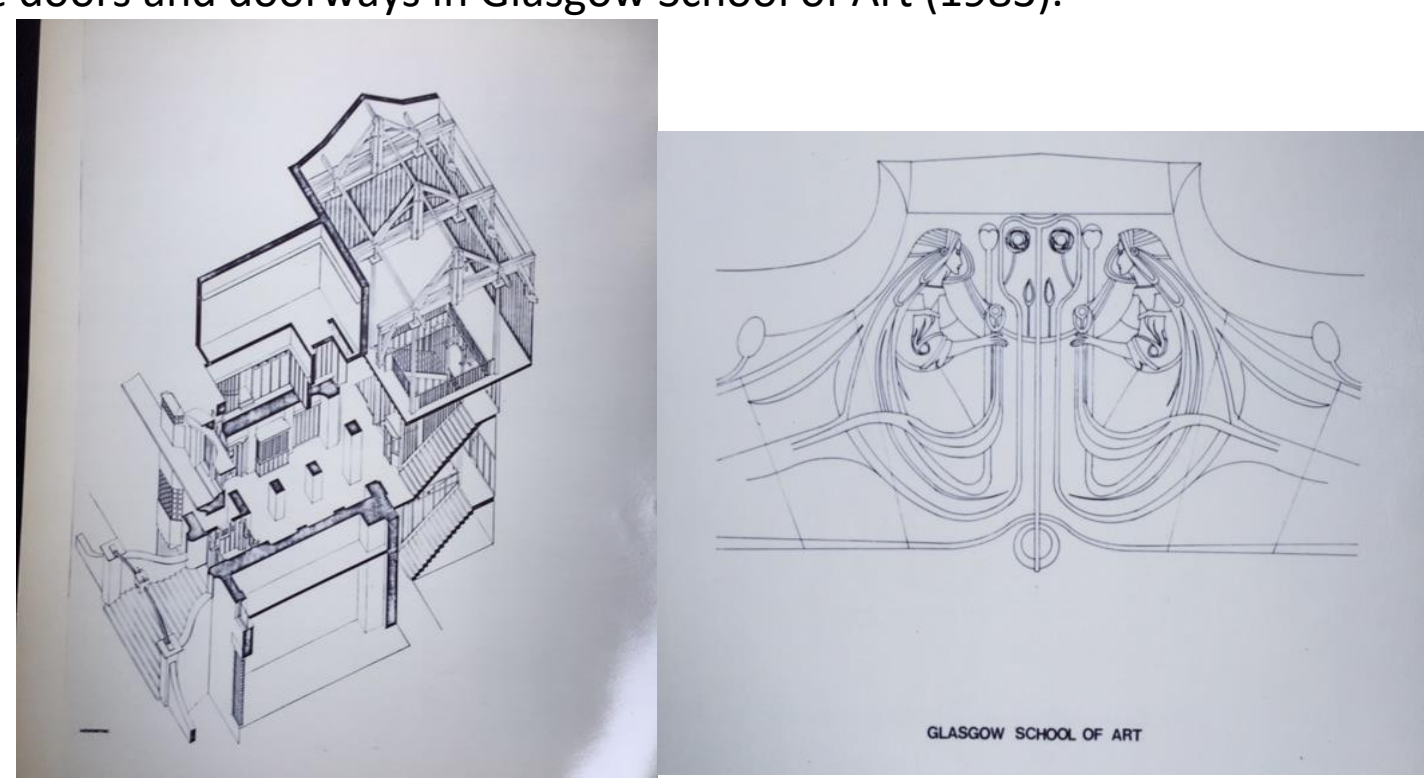

Harrigan's drawings constitute a vital complement to Mackintosh's plans and sections and allow for a 'critique' of the volumetrics of this part of the building, which seems to comprise so many eccentric spaces linked together in an apparently unconventional manner: the vaulted entrance hall with solid square plan piers; the timber cage of the main staircase with the janitor's box hanging out into the void; the director's office with the deep off-centred embrasure to its main window and the director's studio above it, those latter two rooms fronted by balconies, one with a stone parapet and one fenced.

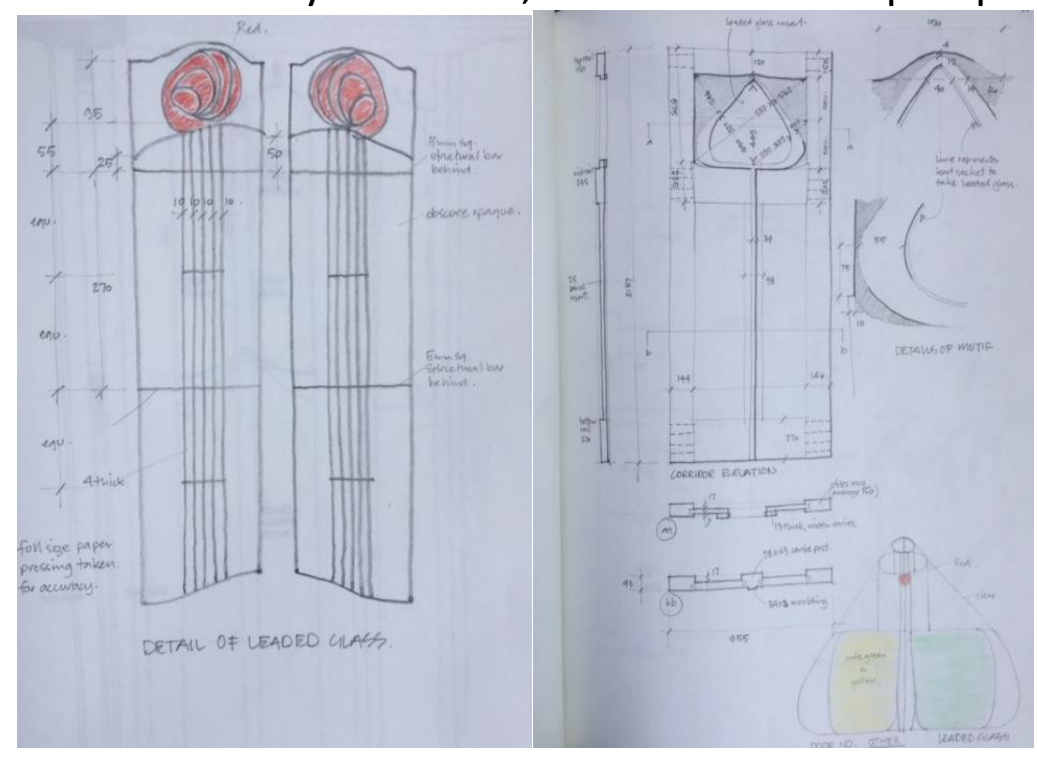

Cooper and Moir's study of the doors in detailed drawings $[7,8]$ provide another crucial piece of the jigsaw in understanding the evolution of 
Mackintosh's work. In supplying a rigorous assessment through drawing about which doors are original and why, it allows us to make certain judgements regarding the relationship between colour and form, openings, volume, and solid and void relationships and the notion of the Gesamtkunstwerk as exploited by Mackintosh. While Mackintosh's walls are, as demonstrated above, far from inarticulate, nonetheless the doors in the building perform a role which recalls something of Georg Simmel's dictum 'Walls are mute. Doors speak. ${ }^{\prime 15}$

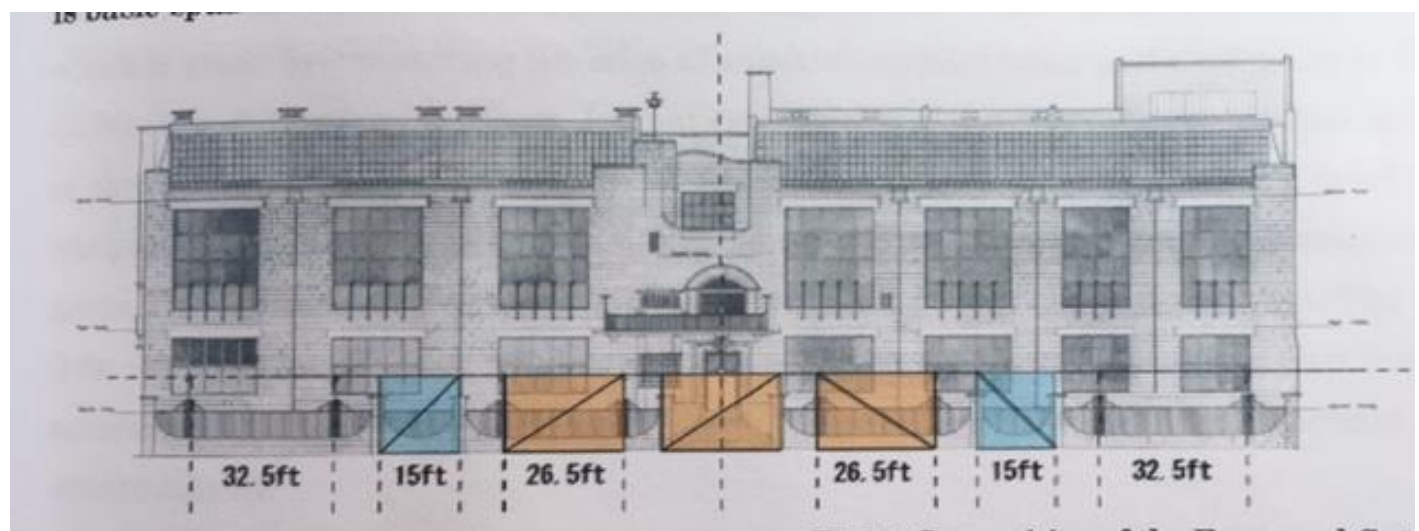

Fig14. Composition of the Fence and Gat
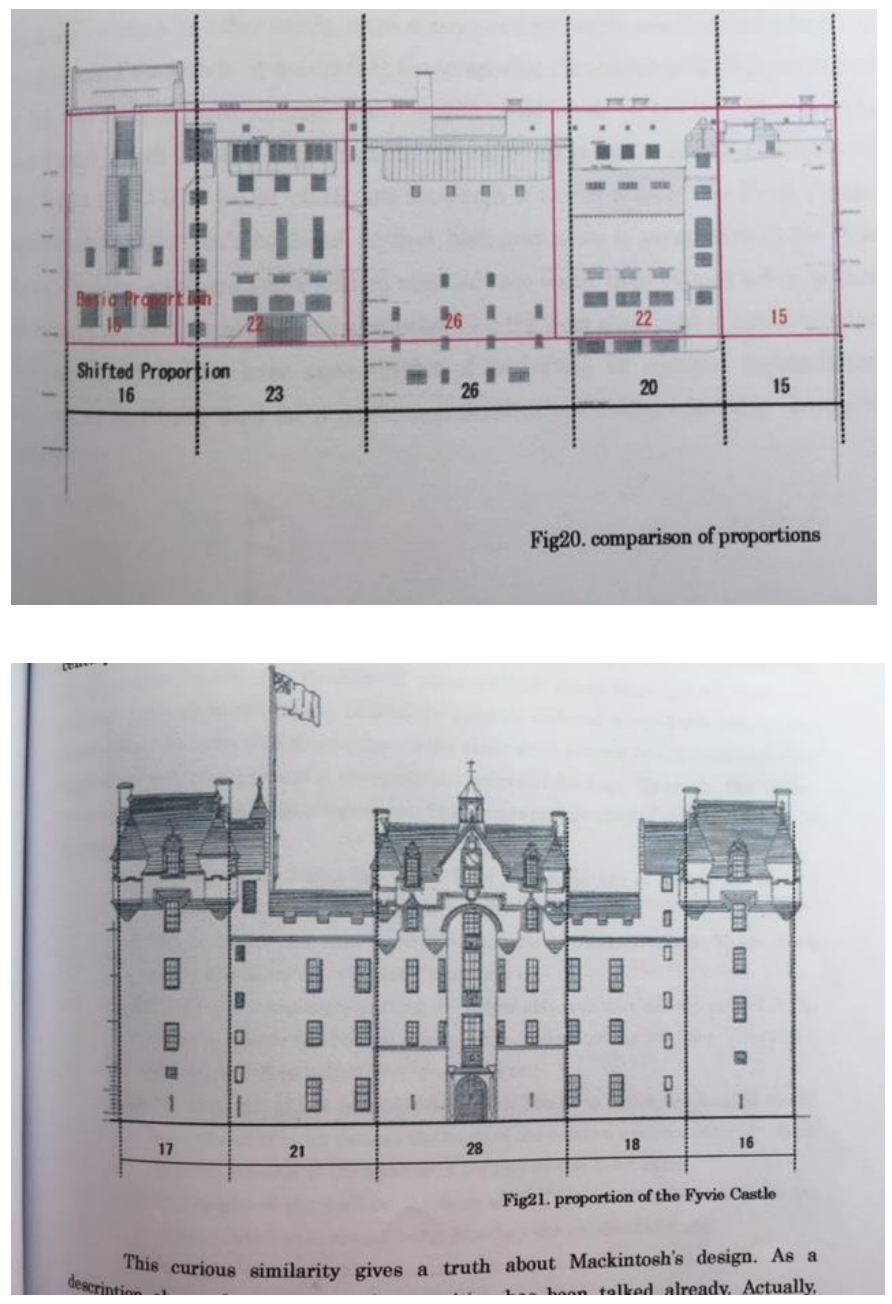
Various studies over the years also examined the technical aspects of Mackintosh's design. Takuji Hasegawa's dissertation looks at proportion, symmetry and asymmetry, and the use of modules in Mackintosh's work [ 9 a,b.c]. ${ }^{16}$ It also subjects the oft-cited comparison of the proportions of the neoBaronial Fyvie Castle with the southern façade of GSA to rigorous and measured examination. These drawings and measurements, and the speculations and analyses contained there regarding proportion and symmetry and the models and parameters used by Mackintosh, demonstrate the strong structural discipline which underwrites the architect's work. It demonstrates that, while Mackintosh was a master of poetic development in space and forms, as seen in his appropriation and elaboration of Japanese motifs, it was that underlying structural discipline, exposed at least in part by Hasegawa's drawings, that, as MacMillan notes of the GSA building, 'saved it from eccentricity or artistic licence'.

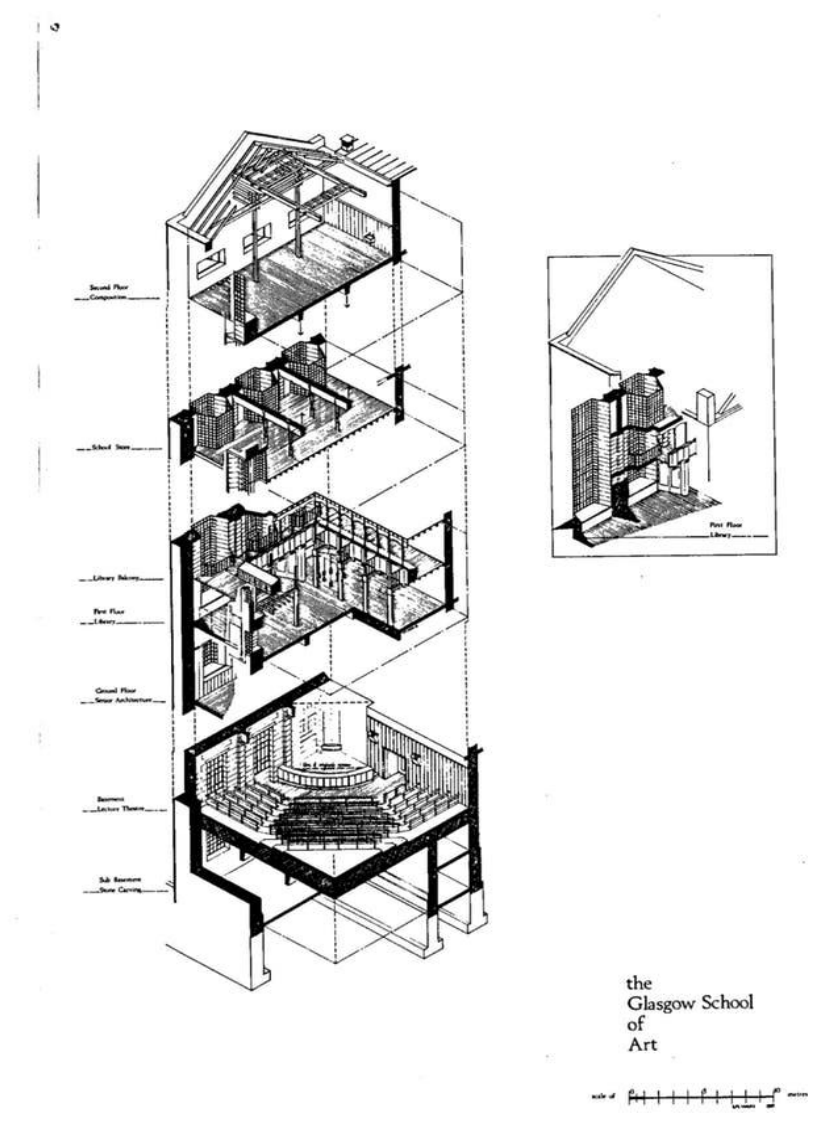

George Cairns completed the second PhD on Mackintosh's Glasgow School of Art in 1992, although the first to interpret the building through drawing [10]. ${ }^{17}$ His thesis set out to analyse the original plenum heating system installed in the building and provides us with an understanding of how the service spaces were incorporated into the volumetric designs and run through 
and around the habitable spaces. Cairns work, through drawing, thus helps to demonstrate how Mackintosh went beyond the aims of the English or Artsand-Crafts movement to incorporate modern technologies and techniques, including machine-planed timber, electric light, heating, 'air conditioning' and plate glass into a designed and crafted whole.

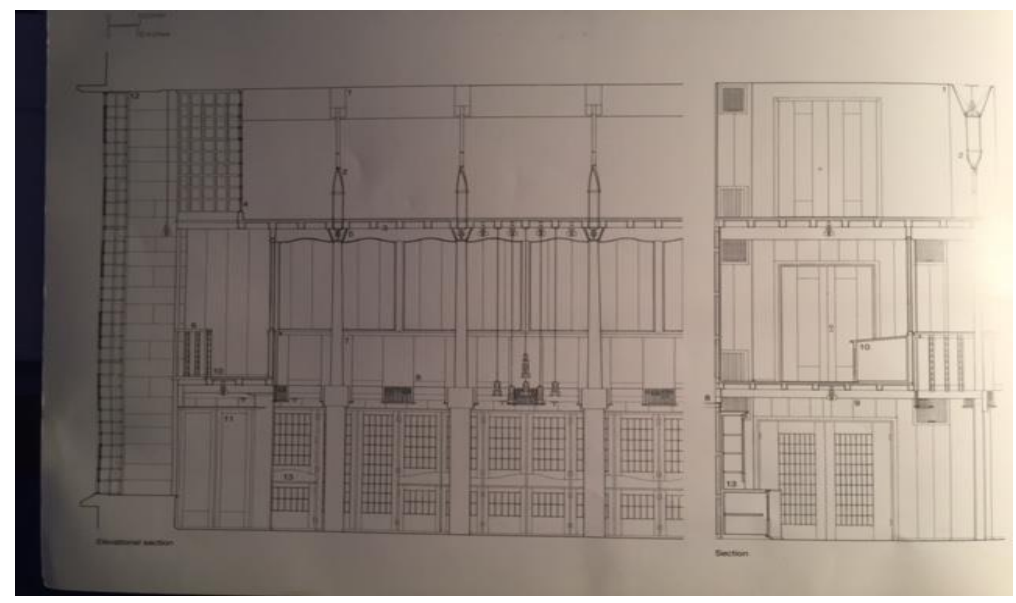

A less technical study, but one which in its poetic understanding of Mackintosh's work has proved very useful for the teams rebuilding the library since the 2014 fire, was Paul Clarke's production of drawings for the book he produced on Glasgow School of Art in the Phaidon 'Architecture in Detail' series, published in 1993 with former Head of Architectural History at the Mackintosh School of Architecture, James Macaulay. ${ }^{18}$ Clarke's clean and fine drawings were not only much used in the first rebuilding work, [11] but they were also copied without acknowledgement in other publications made elsewhere in the world. ${ }^{19}$

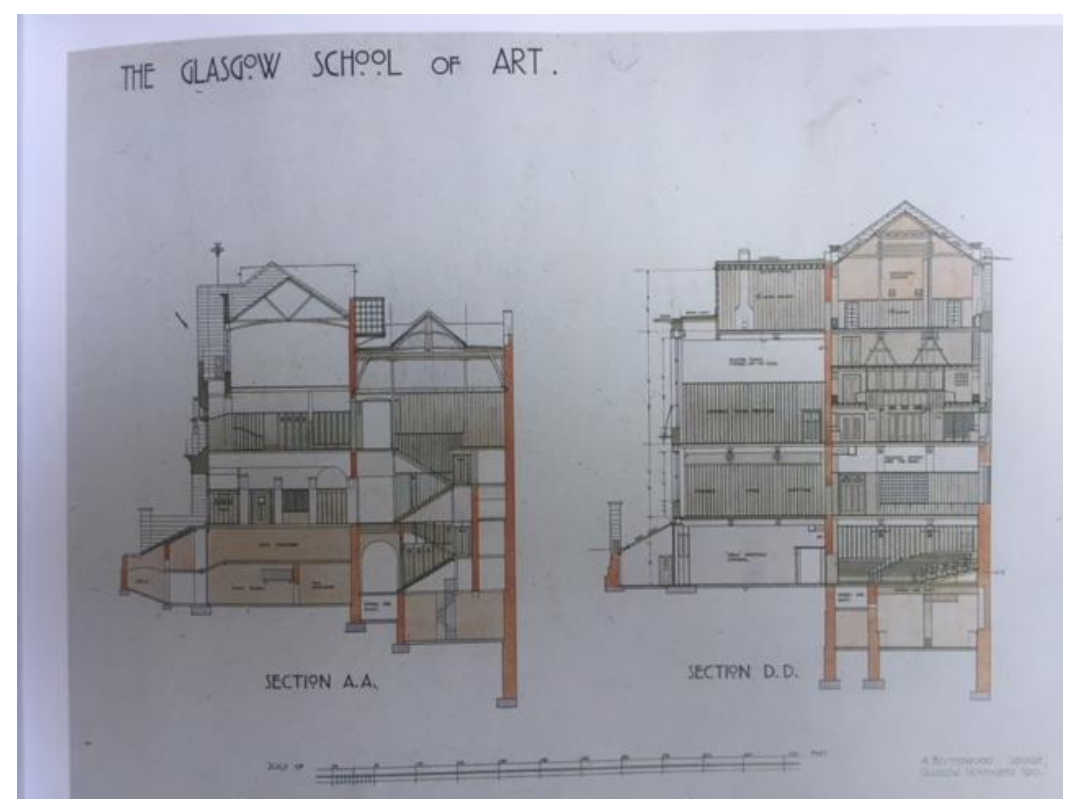


Decades of critical meditation on Mackintosh's work have led to led to theories about his method of working, the qualities of his finished work and the relationship between his drawing and building. One exemplary debate carried-out through drawing work concerns the role of the section in Mackintosh's work, and what that means for his conception and use of space. His fine N-S cross sections in both the 1907 and 1910 selections of drawings [12] are well known, and constitute a vital tool in understanding the building in its situation as they 'deliberately celebrated the sloped condition of the site'. ${ }^{20}$

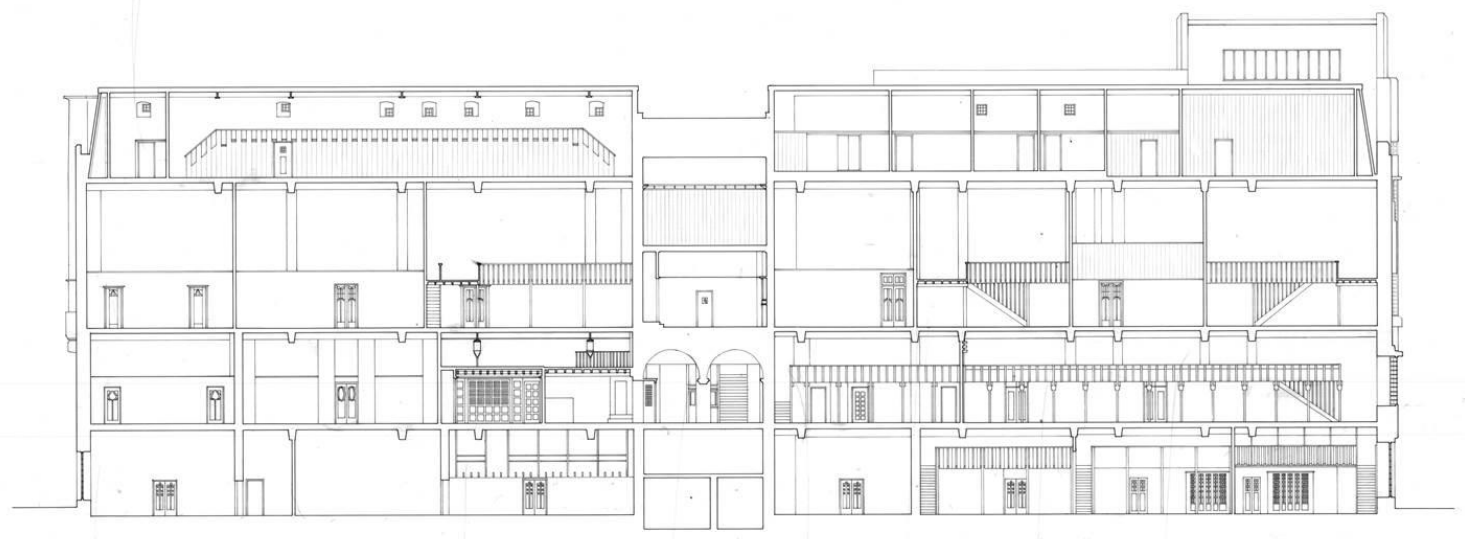

It had long been noticed that, however, despite the fact that it occupies one full length of the Glasgow city grid block - no longitudinal section drawing had ever been found as drawn by Mackintosh. Indeed, it was not until 2003 that the first measured set of longitudinal section drawings were prepared by student Sorrel Challands for her dissertation [13]. ${ }^{21}$ Challands south-facing longitudinal sections are complemented by the preparation of north-facing sections in a 2005 dissertation by Robert Moore, ${ }^{22}$ and supplemented by further drawings and telling commentary in the text of a dissertation by Maeve Magennis in 2014..$^{23}$ The very production of these drawings provokes further questioning in search of an explanation for the absence of this key organisational and descriptive instrument from Mackintosh's creative and critical toolkit as he designed this relatively large public building. Could that absence be substantial evidence in the prosecution of Robert Mantho's theory 
regarding the weaknesses of Mackintosh's intimate architectural language when it comes to the design of large scale buildings? ${ }^{24}$ While conceding that Mackintosh's significant contribution to architectural culture is characterised by his intricate detail, placement of colour and human scale, Mantho claims that 'the most telling demonstration of the limits of Mackintosh's personal architectural language is his entry for the Liverpool Cathedral competition' in 1903 where, in this 'immense' design, 'Mackintosh's forms lose their elegant line at such a large scale', being 'overwrought' and 'visually awkward' and, worse still, 'would result in restricting the natural light in the interior'. He further claims that when the delicacy and intimacy of the personal architectural language Mackintosh used on small and medium scale buildings 'required re-invention' both to follow typological expectations and in attempt to use symmetrical composition to bring order to large public buildings, e.g. the unbuilt Liverpool cathedral, then 'his natural expression is repressed'.

The absence of a longitudinal section in the case of the design of Mackintosh's most successful public building does not, however, play a part in Mantho's argument about the limitations of Mackintosh's style. Indeed, it is interesting that Mantho makes an exception of the case of the west elevation of the Mac. Mantho writes of that elevation of the Mac as his 'most assured handling of a large scale architectural problem', but he qualifies that approbation by noting that the scale of that part of the work is of large domestic rather than public scale. I will not reproduce this argument in further detail here, but the significant point is that it is provoked and amplified as an architectural problem through both the production and critical examination of drawings of the Glasgow School of Art.

\section{The future, and drawing Mackintosh}

Whatever decisions are made regarding the future of Mackintosh's Glasgow School of Art building, the representative selection of works illustrated and discussed here demonstrate a rigorous and scholarly tradition of sustained architectural inquiry through drawing which sometimes takes on an academic tone, sometimes an artistic one, but carried out via the tools of the discipline of architecture. This work could be compared usefully with the series of records through drawing made by Oska Sosnowski's Warsaw Polytechnic students in the 1930s and during WWII which were subsequently used extensively to inform the 1950s rebuilding of historic Warsaw after it had been largely destroyed by the Nazis. ${ }^{25}$ Although this sustained and concentrated research on the Mac school takes its impetus from the oeuvre of a former student of the Glasgow School of Art born 150 years ago, the work itself does not date in terms of its ongoing and vital contribution to the discipline. This is 
ultimately because of the engagement of the work with a timeless and fundamental principle, namely drawing, as a relationship between looking and making.

It has always been clear that drawing was central to Mackintosh's art not least in the light of his career as a painter subsequent to the completion of his major architectural works. It has indeed been a staple of Mackintosh studies for decades, and all the major theoretical studies of his work, including those of MacMillan, Macaulay and Clarke, and Brett, ${ }^{25}$ are hinged upon the constitutional role of the graphic in his oeuvre. Following the 2014 fire, a new urgency was given to this understanding of the fundamental function of the graphic in the Glasgow School of Art. Exemplary work in the archive was sought out by PagePark Architects in their task to partially rebuild, and many of the above graphic studies - especially those of Paul Clarke and George Cairns were examined and exploited in their recreation of the burnt-out West end of the building.

With the 2018 fire, however, the extent of the damage was so great that we are forced to view all the drawings of this building in a different light. The fact that the building was near-completely destroyed, but that innumerable drawn studies in different graphical styles and languages still exist, has obliged a further probing of that special ontological relationship discussed above between the architectural drawing and the material of the finished and built architectural work. It appears that in the post-second fire phase that the special relationship between looking and making found in the architectural drawing is radically altered. That is to say, these drawings have taken on a Janus-faced quality, whereby they not only represent, examine, expose and expostulate regarding a prospective model of the putative new Glasgow School of Art to be rebuilt post-2018, but they are also representations and examinations of a building which once stood but which for the large part especially the interior - no longer materially exists. That the fire has indeed heightened that particular representational aspect makes us aware not only of the value of the drawings as examinations of and instructions towards rebuilding and construction, but also their value in themselves as autonomous graphical works. In other words, they do not have a definitive relationship to a complete and materially constructed architectural work of art, but exist in an ambiguous relation to space, place, form and material. Indeed, they have their own form and material which exists both before and beyond any built construction, and their graphic language exposes relations between spaces, openings and closures, circulation, heights and depths, widths and lengths and so on that can be examined and debated. Relative truths and qualitative relationships can be assessed, measured and put into play with one another 
here, and their interrelationships on endless levels, from the thickness of a door and relative speed of its swing, to the depth of a room and its proportional and symmetrical qualities with respect to the rest of the building, the material of the roof, the height of a stairwell riser, and the power of an air conditioning fan, can all be put into discourse with one another here without the necessary mediation of a completed physical building.

This polyvalent proliferation of drawings, drawing styles and languages is what gives Mackintosh's School of Art its unique relationship with graphic culture as a building. The historical form of this relationship is set out above in the vision of the building itself, already as an outcome and demonstration of the virtuosity in drawing skills which are taught in the School, that the building then gathers and shelters the community which practices, teaches and studies that drawing, and ultimately the building itself becomes a model for that drawing activity. If, as proposed above, this production of drawings constitutes the Glasgow School of Art as a 'drawing machine', what would that mean? The thinkers Deleuze and Guattari introduced the notion of the 'machine' in their work in order to view and analyse the world as produced by desire, or as 'a becoming of forces which remains distinct from the history of forms $[. ..]{ }^{26}{ }^{26}$ The 'machine' is envisaged thus as a conglomeration or assemblage which produces the world in flows of material and interactions of forces. A typical example of such a 'machine' appears in the philosophers' work as a 'diagram', ${ }^{27}$ or as the geological process of sedimentation of rock, both of which are representations of forces flowing together, seeing the world as always 'becoming', and avoiding the notion of a world coming into being in any final set form simply through the action of subjects on objects (think of the gradual break down of rock through natural forces, wind rain, pressure, and the sedimentation of the rock and rebuilding of strata, all done without an evident transcendental hand as subject driving the objective process). Deleuze and Guattari are suspicious of a set world of forms and are interested in exposing and investigating the world as 'becoming' as a series of ongoing processes which may only appear to be set forms depending on the speed of their becoming and on the time period over which the interaction with them takes place. Hence, in the Introduction to One Thousand Plateaus, they describe a book as a machine in spatial terms which serve as motifs throughout their work, but which also shows their similarity to that non-transcendental process of the sedimentation of rock. In a book, they write, '[...] there are lines of articulation, or segmentality, strata and territories, but also lines of flight, movements of deterritorialisation and destratification' ${ }^{28}$ Just as Mackintosh's design work is a hybridisation, a locus of intersecting intensities of histories and styles and modes of architectural operation, so then the continual probing, 
discussing, re-imagining and re-inscribing of that work as described above by scholars, architects and artists allows us to envision the Glasgow School of Art as a process of different speeds of formation and development with its own emergent facts and affects from its own immanent properties and materialist operations.

The Mackintosh Glasgow School of Art can thus be viewed as a drawing machine in terms of the continuous production of a series of discrete outputs of drawings, from before the project for an actual building was conceived, to a continuation after it had been destroyed. This production represents relations of forces belonging to stratified formations in the architectural project. In the wake of the fire arises clearly the ambiguity of the actual physical building in terms of whether it is the object which all this drawing produces and to which it is directed, or is the subject itself which stimulates, directs and even desires this flow of representations, or if indeed the physical building, as it was, complete and standing, was ultimately neither the object nor the subject of the Glasgow School of Art architectural project. Thus, the aptness of the application of the Deleuzian model of the machine without a transcendental subject also becomes clear, and we can envisage the machine that is the Glasgow School of Art. Viewed in this light, the actual physical construction, it might be said, is not necessarily The Glasgow School of Art. That physical building is only a part of the drawing machine (and not necessarily a principal, a priori, or fundamental part), a machine which operates to produce flows of representations, understandings, trials and expositions of all the relatively crude forces proper to architecture as set out by Schopenhauer and Kant ${ }^{29}$, namely gravity, plasticity, light, density heat and so forth, alongside other social forces like pedagogical teaching methods and traditions, academic and professional protocols, practices of dissemination and codes for publication, archiving and so endlessly on.

The output of this machine, which is constituted largely by the scholarly architectural and artistic inquiry and debate around Glasgow School of Art, takes place between students and teachers, undergraduates, postgraduates, professors and tutors; it is to be found in the productions of the school personnel, in publications by staff, the dissertations and theses by students held in the library, and other drawings and work in the archives. The scholarly, academic, artistic and architectural works do not, however, constitute the only active and meaningful field of operations which play out. One vital aspect of the 'machine' as envisaged by Deleuze and Guattari is its interpenetration and interaction with its environments, and in particular with the social and political environment which give the 'assemblage' its significance and elaborate its role as a sign. There are manifold levels of operation in socio-political networks by 
the Glasgow School of Art machine which contextualise the above graphic, artistic and professional networks of interactions through drawing and critique. Levels which could be considered in the realisation that the Glasgow School of Art is not, nor ever was, solely and simply a self-standing form on Renfrew Street, would include the design impetus and source, and the use and functionality of the building.

Consideration of the impetus - the need for a design school in a major industrial city at the heart of nineteenth century imperial Britain, and the hybrid, contingent and heterogeneous sources of the design (as described above) - can help us to deconstruct various mythologies - 'The Glasgow Style', 'Art Nouveau', 'the lone genius' - that were apparently embodied and reified in the stones of the building. And, indeed, it is at that level of function and use, that we realise that the appearance of a multifaceted functionality may, in fact, have been a contributory factor to the building's demise. Use of the building over the past few years has altered, to focus on its public role as an 'attraction' which embodies those stone-cold myths mentioned above. This has meant that not only were tens of thousands of paying tourists per year guided around the building on a daily basis while it operated as an art school but, somewhat paradoxically, its role for art students also adopted that role as an 'attraction'. It had been decided by the directorate that student numbers could be boosted, and funding streams secured more easily and steadily, if the promise was made that all new first year students would be housed in the 'Mac' rather than in any of the thirteen other unmythologised buildings on the GSA campus. With these changes in use, and in externally and internally reflected attitudes and constructed meanings around the building, and with the attraction of thousands of previously unwelcome visitors, it may appear that the building housed an overall vitality in its ultimate years. Yet perhaps it was only traversed by, and teeming with, sets of contrasting, conflicting and irreconcilable operations and meanings - like creating original art and consuming ready-made mythologies - which ultimately made for conditions impossible for the building to sustain.

If the decision is made to rebuild the Glasgow School of Art again, then the drawing materials discussed here will once more be put to instructional use. But perhaps more consideration should be given to the environment in which, and with which, that drawing machine will operate, and which will lend it its social and political significance to complement its great architectural significance. 


\section{Notes}

${ }^{1}$ Andrew MacMillan, 'A Modern Enigma: A Paradox of Reduction and Enrichment', in Mackintosh's Master Work: The Glasgow School of Art, ed. William Buchanan (Edinburgh: A \& C Black, 1994), pp. 51-72, p. 51.

2 Plato, The Republic, trans. by Desmond Lee (London: Penguin, 1975).

${ }^{3}$ Roger Jones and Nicholas Penny, Raphael (New Haven: Yale University Press, 1983), pp.199-202.

${ }^{4}$ Johnny Rodger, 'Putting Holl and Mackintosh in Multi-Perspective: The New Building at the Glasgow School of Art', arq: Architectural Research Quarterly, 17:1 (2013), 2-14 ; Johnny Rodger, 'The Revolution will Be Painted: A Study of the Struggle to Build New Architecture in Late Victorian and Edwardian Glasgow', Visual Culture in Britain, 16:3 (2015), 285-307.

${ }^{5}$ Rodger, 'Putting Holl and Mackintosh in Multi-Perspective'.

${ }^{6}$ David MacGibbon and Thomas Ross, The Castellated and Domestic Architecture of Scotland from the $12^{\text {th }}$ to the $18^{\text {th }}$ centuries (Edinburgh: The Mercat Press, 1971). First published in 5 volumes 1887-1892.

${ }^{7}$ See Mackintosh's paper on the Baronial, and Frank Walker's editorial for it, in Pamela Robertson, Charles Rennie Mackintosh: The Architectural Papers (Edinburgh: White Cockade, 1990), pp.153-180.

${ }^{8}$ Thomas Howarth, Charles Rennie Mackintosh and the Modern Movement (London: Routledge, 1952).

${ }^{9}$ Niklaus Pevsner, Pioneers of Modern Design: From William Morris to Walter Gropius (London: Penguin, 1949).

${ }^{10}$ Mackintosh, dir. Murray Grigor, 1969, 34 mins.

${ }^{11}$ Peter Porteous and Paul Spear, The Glasgow School of Art: A Measured Study, unpublished dissertation, Glasgow School of Art, 1971.

${ }^{12}$ William A Coltart and lain W Bailey, A Detailed Measured Study of the Glasgow School of Art, unpublished dissertation, Glasgow School of Art, 1982. ${ }^{13}$ John Harrigan, A Survey and Report on the Centrepiece of the Glasgow School of Art, unpublished dissertation, Glasgow School of Art, 1987.

${ }^{14}$ William Cooper and Peter Moir, A Detailed Measured Study of the Doors and Doorways of the Glasgow School of Art, unpublished dissertation, Glasgow School of Art, 1983.

${ }^{15}$ Georg Simmel, 'Bridge and Door', Theory, Culture and Society, 11 (1994), pp.5-10. First published 1909.

${ }^{16}$ Takuji Hasegawa, Charles Rennie Mackintosh: composition and geometry of Glasgow School of Art, unpublished dissertation, Glasgow School of Art, 2006. ${ }^{17}$ George M. Cairns, Glasgow School of Art: An Architectural Totality, unpublished doctoral thesis, Glasgow School of Art, 1992. 
18 James Macaulay, Glasgow School of Art: Charles Rennie Mackintosh (London: Phaidon, 1993).

${ }^{19}$ Nikolaus Pevsner, Charles R. Mackintosh, trans. by Heather Roberts (Venice: Canal, 1997).

${ }^{20}$ Maeve Magennis, Drawing Mackintosh's Masterpiece: The Glasgow School of Art, A Sectional Study, unpublished dissertation, Glasgow School of Art, 2014, p.17.

${ }^{21}$ Sorrel Challands, The Glasgow School of Art: A History in Section, unpublished dissertation, Glasgow School of Art, 2003.

${ }^{22}$ Robert Moore, The Glasgow School of Art: The Appreciation of the Section, unpublished dissertation, Glasgow School of Art, 2005.

${ }^{23}$ Magennis, Drawing Mackintosh's Masterpiece.

${ }^{24}$ Robert Mantho \& Drew Plunkett, Speculations on an Architectural Language (Glasgow: Charles Rennie Mackintosh Society, 2007), pp.10-13.

${ }^{25}$ David Crowley, Warsaw (London, Reaktion, 2003). p.47.

${ }^{26}$ David Brett, C.R. Mackintosh: The Poetics of Workmanship (London:

Reaktion, 1992).

${ }^{27}$ Gilles Deleuze, Foucault, trans. by Sean Hand (Minneapolis: University of Minnesota Press, 1988), p.86.

${ }^{28}$ Ibid., p.34.

${ }^{29}$ Gilles Deleuze and Felix Guattari, $A$ Thousand Plateaus: Capitalism and Schizophrenia, trans. by Brian Massumi (Minneapolis: University of Minnesota Press, 1980), p.3.

${ }^{30}$ Arthur Schopenhauer, The World as Will and Idea, trans. by Jill Berman (London: Everyman, 1995), pp.135-9. First published 1819; Immanuel Kant, The Critique of Judgement, trans. by Nicholas Walker (Oxford: Oxford University Press, 2007). First published 1790.

\section{Image credits}

arq gratefully acknowledges:

Glasgow School of Art: all images

\section{Author biography}

Johnny Rodger is a writer and critic, and Professor of Urban Literature at the Glasgow School of Art. He is founding co-editor of the literary arts quarterly The Drouth and his latest published books include Spatial Justice: The Architecture of the Scottish Court (Fairleigh Dickinson Uni Press, 2018) and The Hero Building: An Architecture of Scottish National Identity (Routledge, 2016).

\section{Author address}


Johnny Rodger

j.rodger@gsa.ac.uk

\section{CAPTIONS}

11897 Elevation drawing, Charles Rennie Mackintosh, showing elevations of East and West Ends of Glasgow School of Art.

21907 Elevation drawing, Charles Rennie Mackintosh, showing elevations of East and West Ends of Glasgow School of Art.

31910 Elevation drawing, Charles Rennie Mackintosh showing elevation of West End of Glasgow School of Art.

4 Plan of Ground Floor, Peter Porteous and Paul Spear, 1983.

5 Axonometric of Centrepiece, John Harrigan , 1987.

6 The Keystone of the Main Doorway, John Harrigan, 1987.

7 Detail of Leaded Glass on door to the Antique School, 1st Floor, William Cooper and Peter Moir, 1983.

8 Door to staff and tutor rooms, ground floor, William Cooper and Peter Moir, 1983.

9a Composition of Fence and Gate, Takuji Hasegawa, 2007.

9b South Elevation proportions, Takuji Hasegawa, 2007.

9c Proportions of Fyvie Castle, Takuji Hasegawa, 2007.

10 Axonometric of the west end, George Cairns, 1992.

11 Section of Library Interior, Paul Clarke , 1993

12 N/S Section of Glasgow School of Art, Charles Rennie Mackintosh, 1910.

13 E/W Section of Glasgow School of Art, Sorrel Challands, 2003. 


\section{WEB ABSTRACT}

The Glasgow School of Art has a long history of cultivation of the art of drawing. Many types of drawing have been taught and practiced within the institution since its establishment in 1845. Mackintosh's Glasgow School of Art building, completed between 1897 and 1909, can be seen as one great designthrough-drawing outcome of that tradition. The building not only subsequently sheltered and thus enabled a further cultivation of the art of drawing, but became itself a model for the practices of that drawing tradition. There is a strong body of work, much of it by the teachers and students of the school, which has focussed on the building and explored through drawing the architectonic features and significance of the structure. This work has been useful as a teaching and critical aid but also as a contribution to the art and discipline of architecture. In the wake of the first 2014 fire, which destroyed part of the building, this body of work suddenly became of use as a design tool rather than simply an exploratory or critical tool, as the institution sought to reproduce exactly what had been lost. The most recent 2018 fire wreaked a destruction much more comprehensive across the whole building. Accordingly we are forced to completely review the relationship of that drawing heritage to the building. The building that is to say, largely no longer exists, such that the drawings take on aspects of a life of their own not previously attached to them. The school may, however, be rebuilt, recreated 'as was' at some point in the future, potentially instigating yet another type of relationship between the existing drawing work and a new 'Mackintosh' building. 